\title{
NASA dreaming of a permanent base on the Moon...
}

\section{Washington}

FIVE contracts for studies of the utility and feasibility of a manned base on the Moon will be awarded this week by the US National Aeronautics and Space Administration (NASA). The contracts are small, in total worth only $\$ 1.2$ million a year, and they certainly will not launch any astronauts. But they do give a little substance to the dreams that NASA would like to make reality.

NASA has been having difficult times. The most pressing problems are obvious: space launches have fallen years behind schedule, the shuttle has suffered a tragic accident, and an unwise decision was made to abandon expendable launch vehicles. But the more fundamental concern, as Barney Roberts, Mission Manager for the Advanced Program Office at NASA put it, is that "we are no longer respected. We don't have a space station as the Russians do. The Japanese and Chinese have worked very hard and achieved space capabilities. We are becoming secondrate. We now feel a lot of pressure from Congress, the President, the National Science Council, and the public to get things going."

Reports have come out one after another from the National Commission on Space, the Space Science Board of the National Research Council, and several of NASA's own committees. All come to much the same conclusion: NASA must try to return to the heady days of the Apollo programme and have a bold, longterm project that makes US space supremacy obvious to the world. The most influential of the reports, that of the National Commission on Space, whose members were appointed by President Ronald Reagan, declared for a Mars colony last year and celebrated the possibilities of life in space with an artist's impression verging on the psychedelic. More recently, NASA announced that it is studying four initiatives to give the United States a major goal in space; an expanded study of Earth systems, more Solar System exploration, a permanent base on the Moon and human exploration of Mars.

The pressure has been strong to go for Mars; conferences have been organized and Congress lobbied. But there are signs that NASA will leave some of its options open by trying to win support for a Moonbase, that could later provide a step towards Mars. An attractive feature of the Moon is that it could be mined to provide the raw materials for further voyages. Forty per cent of weight of the lunar soil is oxygen. If that could be extracted, rockets could obtain the heaviest component of their fuel in space. There is also plenty of silicon for solar cells and meteorite bombardment has provided relatively pure iron ore which can be picked up with a magnet.

As a percentage of gross national product, the National Commission on Space has calculated that a lunar base would cost less per year than the Apollo project, although it would run for longer. Man could be back on the Moon by 2000 , with a permanent base five to ten years later. The studies commissioned this week are but a tiny step in that direction. Lockheed Corporation will manage two projects to look at uses that could be made of a Moon base, and at new space vehicles to operate in its vicinity. Two further projects will aim at seeing how the different activities of a base could be integrated overall. One has yet to be awarded. The other goes to the University of Texas and the Large Scale Programs Institute, Austin, to develop a computer model of the systems needed to run the base. The final project goes to the University of California, San Diego, to study methods of transport that do not use chemical rockets, including space tethers - miles of wire that could be used to winch spacecraft in and out of orbit.

The idea of a Moon base has already set scientists dreaming - even though most of them would be in their rocking chairs before it could actually be built. An unofficial group centred on the University of New Mexico has been looking at whether the Moon could offer anything unique for

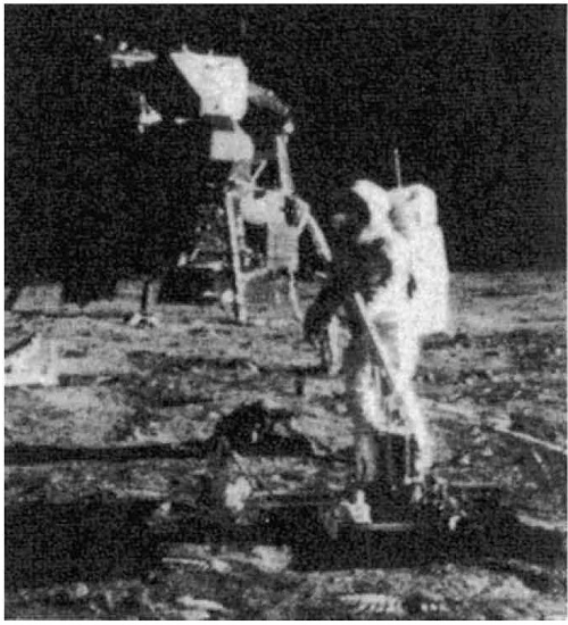

We'll be back? Edward Aldrin deploying a seismic experiments package back in the heady days of the Apollo programme, 1969.

astronomers. It seems that it could. An observatory on the hidden side of the Moon would be sheltered from disturbances produced by the Earth. That means it would be possible to open up astronomy at new, very-low frequencies that auroral kilometric radiation would prevent in an Earth-orbiting observatory.

Optical and infrared interferometry could take advantage of the totally clear lunar atmosphere and the extreme stability of a baseline measured on the Moon's geologically dead surface. With a tenkilometre baseline, resolution at the middle of the optical region could be as good as one microarcsecond, five times the planned resolution of the Hubble Space Telescope. Use could even be made of huge lunar craters to build 'natural' radio telescopes, like that at Arecibo.

Alun Anderson

\section{... and facing down-to-Earth problems}

\section{Washington}

RESUMPTION of US space shuttle flights has been delayed yet again. The target date for the first launch since the loss of the Challenger is now June 1988, four months later than the date announced last October.

Even the June date may be optimistic. Two large-scale tests must be performed on the shuttle's main engines, as well as a series of tests on the solid-fuel boosters that caused the 1986 accident. The new plan assumes that all tests will be successful and allows no time for possible mishaps.

Only three launches will now be possible in 1988 and seven in 1989 and there are bound to be further delays for science missions. Waiting in line for an early launch are the Hubble Space Telescope, the ultraviolet astronomy telescope (ASTRO-1), the Venus radar mapper (Magellan), the Jupiter mission (Galileo) and the solar polar mission (Ulysses), along with communications and defence satellites.

Some satellites originally planned for the shuttle will be launched by the conventional rockets that the shuttle was intended to replace. After a year of rumours, NASA confirmed last week that it will acquire expendable launch vehicles to try, as NASA administrator James Fletcher put it, "to accelerate the deployment of the nation's backlog of space science missions". The West German X-ray satellite ROSAT, the Combined Release and Radiation Effects satellite, and the Extreme Ultraviolet Experiment will be the first to benefit with launches in 1990-91. One of the larger planetary missions may be launched aboard a massive Titan rocket, but a decision whether to do so will not be made for some months.

Early launches will be made by buying rockets tailored to the already designed payloads. Later, competitive bids from industry will be taken in line with the Reagan administration's policy of commercializing the market for expendable launch vehiles. 